\title{
Promising Technologies of Mining and Processing of Solid Minerals
}

\author{
Sergey Shabaev ${ }^{1 *}$, Seregey Ivanov $^{1}$, and Evgeniy Vakhianov ${ }^{1}$ \\ ${ }^{1}$ T.F. Gorbachev Kuzbass State Technical University, 650000, 28 Vesennyaya St., Kemerovo, Russia
}

\begin{abstract}
The continuing growth in mineral extraction entails an increase in industrial waste, which in turn has a negative impact on the environment. Rubber-tired vehicles, in which the tires wear colossally, is mainly used as a transport for loading, unloading, transportation and other types of work in the extraction of solid minerals. The used tires are not disposed in any way, but are stored in special areas where harmful toxic substances are emitted under the influence of ultraviolet rays. Therefore, a decision was made to find a method for utilization and rational use of industrial waste in the road construction sector.The operating temperature of composite rubber-bituminous binders based on rubber crumb from the used automobile tires is estimated in this paper, which is necessary for assigning technological parameters of production and laying of asphalt-concrete mixtures produced on their basis. It is established that composite rubber-bituminous binders based on rubber chips from the used automobile tires, produced according to the twostage technology, have the same viscosity as the original petroleum bitumen, at a temperature increased by $20^{\circ} \mathrm{C}$.
\end{abstract}

\section{Introduction}

The increase in coal mining in Kuzbass leads to the ever-increasing number of used equipment. Rubber-tired vehicles are mainly used at open pits and other industries. Because of the heavy load on the tires of heavy equipment, there is a rapid wear of these units. In this regard, there is the acute problem of utilization of tires, which are currently stored in specially designated areas where toxic substances are released under the influence of ultraviolet rays.

At present, both in the Kuzbass and in Russia, plants for processing the used tires to produce the various fractions of rubber crumbs are being put into operation. However, due to the fact that the amount of used tires is many times greater than the real consumption of rubber crumbs, this type of waste continues to be accumulated in specially designated areas.

The most promising method of recycling rubber crumb, produced from the used automobile, is its use in road construction, as a modifier of bituminous binders.

\footnotetext{
*Corresponding author: Shabaev81@rambler.ru
} 
There are various technologies for bitumen modification in the world practice: Asphalt Rubber [1-9], Terminal Blended [10] and their combinations [11, 12]. The rotational method for determining their viscosity is the most common. In this case, the highest kinematic viscosity is normalized, which should be $8.65 \mathrm{~mm}^{2} / \mathrm{s}$ at $100{ }^{\circ} \mathrm{C}$. At the same time, devices designed to determine the kinematic viscosity of rubber bituminous binders are designed to determine the viscosity of sufficiently thick materials, such as rubber bituminous binders, while they are practically unable to assess the viscosity of bitumen at operating temperature. However, rubber bituminous binders produced according to the two-stage technology have a significantly lower viscosity than rubber bituminous binders produced according to other technologies, therefore, the task of their viscosity comparing with the original bitumen is actual.

\section{Materials and methods}

When carrying out the studies, the relative viscosities of БНД 60/90petroleum bitumen from Omsk refinery and the composite rubber-bitumen binder produced on its basis according to the following two-stage technology were estimated:

a rubber crumb in an amount of $37.5 \%$ was added at room temperature into the dispersion medium of bitumen in an amount of $50 \%$ and petroleum oil in an amount of $12.5 \%$ heated with constant stirring to a temperature of $230 \pm 5^{\circ} \mathrm{C}$;

the mixture was kept under constant stirring at a temperature of $230 \pm 5^{\circ} \mathrm{C}$ for 2.5 hours to produce a concentrated slurry of the rubber-bitumen composite;

the heating elements were switched off and bitumen, having a temperature of $105 \pm 5^{\circ} \mathrm{C}$, in an amount of $47.5 \%$, was added to the concentrated slurry of the rubber-bituminous composite in an amount of 52.5\%, and the mixture was held for 0.25-0.50 hours to produce the composite rubber-bituminous binder.

To estimate the operating temperature, the flow time of $50 \mathrm{~cm}^{3}$ of the binder through 5 $\mathrm{mm}$ diameter hole at the bitumen viscometer was measured in accordance with the test procedure. Planning matrix of the experiment is presented in Table. 1.

Table 1. Planning matrix of the experiment to determine the operating temperature of the composite rubber-bitumen binder.

\begin{tabular}{|l|c|c|c|c|c|}
\hline \multirow{2}{*}{ Binder } & \multicolumn{6}{|c|}{$\begin{array}{c}\text { Flow time of } 50{\mathbf{~} \mathbf{m}^{3}}^{\mathbf{2}} \text { of binder, c, at test } \\
\text { temperature, }\end{array}$} \\
\cline { 2 - 6 } & $\mathbf{1 0 0}$ & $\mathbf{1 2 0}$ & $\mathbf{1 4 0}$ & $\mathbf{1 6 0}$ & $\mathbf{1 8 0}$ \\
\hline 60/90 feed bitumen & $\mathrm{Opt}_{1}$ & $\mathrm{Opt}_{2}$ & $\mathrm{Opt}_{3}$ & $\mathrm{Opt}_{4}$ & $\mathrm{Opt}_{5}$ \\
\hline Composite rubber-bituminous binder & $\mathrm{Opt}_{6}$ & $\mathrm{Opt}_{7}$ & $\mathrm{Opt}_{8}$ & $\mathrm{Opt}_{9}$ & $\mathrm{Opt}_{10}$ \\
\hline
\end{tabular}

Note: $\mathrm{Opt}_{\mathrm{i}}-$ optimization parameter.

\section{Results and discussion}

The results of the experiment for determining the operating temperature of the composite rubber-bituminous binder, produced according to the two-step technology, are presented in Table. 2. The graphical form of the obtained dependences is shown in Fig. 
Table 2. The results of the experiment to determine the operating temperature of the composite rubber-bituminous binder.

\begin{tabular}{|l|c|c|c|c|c|}
\hline \multirow{2}{*}{ Binder } & \multicolumn{6}{|c|}{ Flow time of $50 \mathbf{~ c m}^{\mathbf{3}}$ of binder, c, at test } \\
temperature,
\end{tabular}

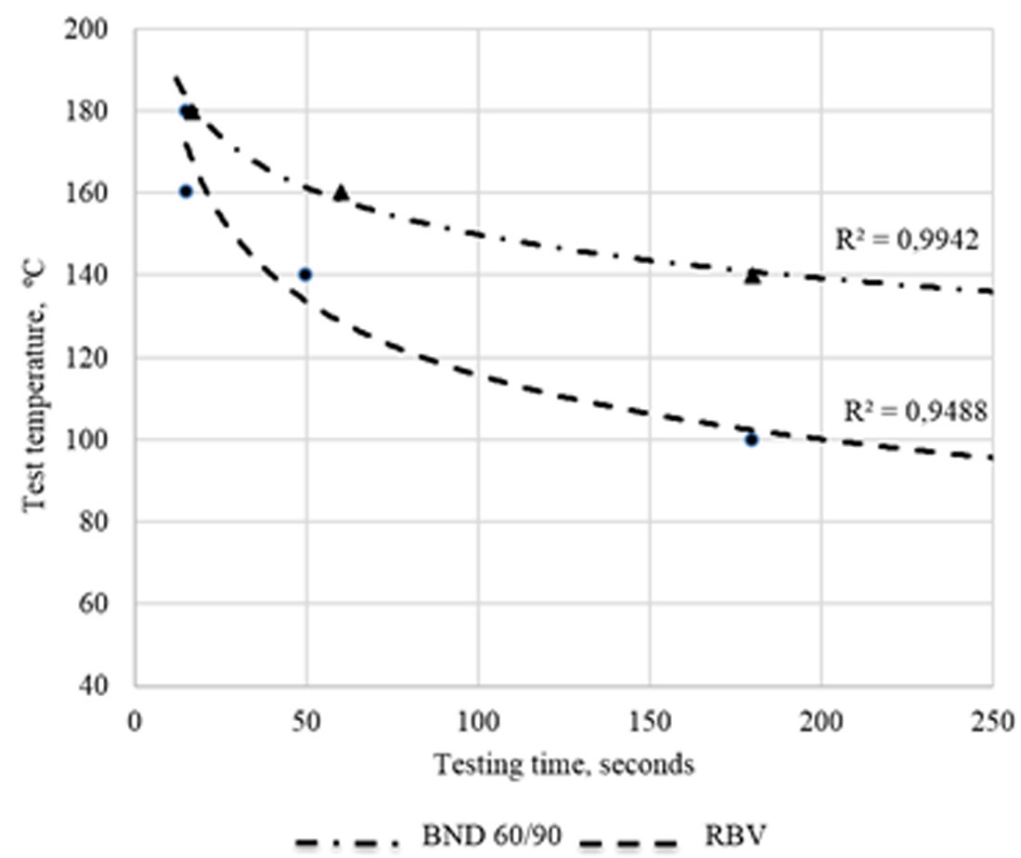

Fig. 1. Dependences of the relative viscosity of the feed bitumen and the composite rubberbituminous binder, obtained on the basis of the feed bitumen at the two-stage technology

The analysis of the results of the experiment shows that the relative viscosity of the feed 60/90 petroleum bitumen at the operating temperature of the asphalt mixes of 145 $155^{\circ} \mathrm{C}$ is $15 \mathrm{~s}$. The composite rubber-bituminous binder has the same relative viscosity at a temperature of $165-175^{\circ} \mathrm{C}$, hence, to ensure the comparable workability of asphaltconcrete mixtures based on the composite rubber-bituminous binders and the bitumenbased asphalt mixtures, their operating temperature should be increased by $20^{\circ} \mathrm{C}$.

\section{Conclusions}

The operating temperature of the composite rubber-bituminous binders, produced according to the two-stage technology, is $20^{\circ} \mathrm{C}$ higher than the operating temperature of the feed petroleum bitumen. In this regard, there will be a decrease in anthropogenic impact on the ecosystems of both mining areas and in other places of the composite rubber-bituminous binder applications. 


\section{References}

1. B. Abdulwarith, H. Norhidayah, M. Hanif, M. Jahangir, Materials and Structures, (2016)

2. M. A. Mull, K. Stuart, A. Yehia Journal of Materials Science, 37, 557 (2002)

3. H. Kim, S. Lee, S. Amirkhanian, KSCE Journal of Civil Engineering, 14, 839 (2010)

4. G. R. Morrison, S. A. Hesp, Journal of Materials Science, 30, 2584 (1995)

5. X. Chuan, L. Tianqing, Q. Yanjun, Journal of Modern Transportation, 21, 273 (2013)

6. S. Shakir, P. Jorge, M. Manuel, 7th RILEM International Conference on Cracking in Pavements, 4, 1157 (2012)

7. M. Tao, Z. Yongli, H. Xiaoming, Z. Yao, KSCE Journal of Civil Engineering, 20, 1347 (2016)

8. R.G. Hicks, D. Cheng, T. Duffy, Evaluation of Terminal Blend Rubberized Asphalt in Paving Applications (California Pavement Preservation Center, 2010)

9. H. Zhu, C. Liu, K. Tom, T. Norasit, Materials and Structures, 41, 383 (2008)

10. G. Juan, A. Ana, G. Felice, Mechanics of Time-Dependent Materials, 20, 389 (2016)

11. A.A. Khristoforova, M.D. Sokolova, S.E. Filippov, B.N. Zarovnyaev, International Polymer Science and Technology, 42, 27 (2015)

12. A.A. Khristoforova, M.D. Sokolova, B.N. Zarovnyaev, A.N. Akishev, Mining Journal, 3, 47 (2016) 